\title{
Indicators of Rural Youth Drug Use
}

\author{
Paul D. Sarvela ${ }^{1}$ and E. J. McClendon ${ }^{2}$ \\ Received November 20, 1986; accepted February 11, 1988
}

The relationships between personal substance use, health beliefs, peer use, sex, and religion were examined using data collected from 265 middle school students in rural northern Michigan and northeastern Wisconsin in January and February 1984. A positive correlation between peer and personal drug use was established. A relationship was also found between health beliefs and personal substance use. In addition, a regression model was able to account for a statistically significant amount of the variance of alcohol, marihuana, and cigarette use in the target population. Recommendations are made concerning future research, methods of improving health education program development, and possible target areas for psychotherapy.

\section{INTRODUCTION}

The problem of early adolescent chemical dependency is one area of drug abuse research that has received relatively little attention in the substance abuse literature. Research focusing on early adolescent populations is necessary because early adolescence is the developmental stage where drug use most commonly begins. Yet this age group has been ignored by most investigators, who have usually concentrated on high school or older age

\footnotetext{
An earlier version of this paper was presented at the 1985 annual meeting of the American Public Health Association, Washington, DC.

'Assistant Professor, Department of Health Education, College of Education, Southern Illinois University, Carbondale, IL 62901. Received Ph.D. in Health Education from The University of Michigan. Research interests include program evaluation, measurement, and community health education. To whom correspondence should be addressed.

2Professor, Program in Health Education, Department of Health Behavior and Health Education, School of Education and School of Public Health, The University of Michigan Ann Arbor, MI 48109. Received Ed.D. in Health Education from Wayne State University. Research interests include school health, international health, and program evaluation.
} 
populations. It is important to examine the indicators of drug use and abuse among early adolescents so common patterns and factors related to the beginning stages of drug abuse can be identified. These findings can then be used in the diagnosis, treatment, and prevention of incipient substance abuse problems.

A number of variables (e.g., genetics, ethnic group, religion, familial influence, age, sex, low self-esteem, internal-external locus of control, health beliefs, and peer pressure) have been hypothesized as being related to drug use behavior. Of these factors, age, sex, religion, health beliefs, and peer pressure have frequently been demonstrated to be successful predictors of drug use.

Age is a variable strongly related to substance use behavior (see, for example, Johnston et al., 1979; Kirk, 1979; Napier et al., 1981; Nyberg, 1979). Nyberg (1979) describes the relationship between drug use patterns and age in terms of a curvilinear function. As age increases, substance use also increases, peaking at the ages of about $18-24$, followed by a general decline in use.

Age is a significant determinant of drug use for many reasons. For example, as adolescents advance in age, their need to behave as adults increases. Some authorities have hypothesized that early adolescents see drug use as one way of expressing "adultlike" behaviors.

Age is also important for reasons related to specific cohort behavioral patterns. The types of drugs that adolescents considered socially acceptable to use in the 1940s are probably totally different from the types of drugs used by adolescents in the 1980s, due to differing cohort values. Each generation has its own taboos concerning specific drug use behaviors.

The decrease in substance use behaviors after the age of about 25 is another age-related occurrence. It may be that once people leave adolescence and young adulthood, the demands and responsibilities placed on them by the family and their jobs preclude high use of drugs.

With regard to sex differences, early research indicated that males used substances at higher frequencies and in larger quantities than did females. These differences are now diminishing, and in some populations there are no longer any significant differences between the substance use behaviors of males and females (Becker, 1977; Eichberg and Bentler, 1976; Kirk, 1979; Tolone and Dermott, 1975).

Religion appears strongly related to drug use behavior. Weschler and McFadden (1979) determined that Jewish-American college students have the highest prevalence rates of drinking, but the lowest frequency of alcohol abuse. They argue that the Jewish religion and culture's acceptance of alcohol has "taught" Jewish youngsters socially acceptable patterns of drinking, which in turn reduce the chance of abusive drinking styles. Cahalen (1970) notes that those people who are more religious drink less, and when con- 
trolling for church attendance, Catholics have the highest drinking rates. Religiosity, as measured by churchgoing behavior, has been consistently shown to be inversely related to substance use (see, for example, Jessor, 1976; Weschler and McFadden, 1979). The more religious the individual, the less likely he or she will drink or use drugs (Gersick et al., 1981).

Several recent studies have explored the beliefs and attitudes adolescents hold toward substance use behaviors (Brook et al., 1977; Erickson, 1982; Hamburg et al., 1975; Hartnoll and Mitcheson, 1973; Johnston et al., 1979; Kamill and Steer, 1976; Kinder, 1975; London, 1982; Seffrin and Seehafer, 1976; Skiffington and Brown, 1981). These studies have examined attitudinal domains such as youth perceptions of legal and social acceptance of chemical use, as well as perceived harmfulness of specific mood-modifying substances.

Hamburg et al. (1975), Johnston et al. (1981), and Skiffington and Brown (1981) found that attitudes concerning the harmfulness of substance use were related to substance use behavior. These findings are supported by Johnston et al. (1981), who suggest that "strong correlations exist between individual use of drugs and the various attitudes and beliefs about those drugs" (p. 85).

Johnston and associates also assessed student perceptions of the health risks involved with drug use and their legal attitudes toward substance use. Their data indicated that the perceived harmfulness of the substance was strongly related to the legality of the drug. This did not, however, apply to marihuana. Heroin, barbiturates, amphetamines, and cocaine all produced large responses reflecting a belief of great harm in their use. Regular use of cigarettes also received that value. Interestingly, few subjects felt experimental use of marihuana was harmful, and only a minority associated much harm with alcohol use.

Perhaps one of the most successful predictors of youth substance use is peer pressure (e.g., Ausabel et al., 1977; Dembo et al., 1980; Levine and Kozak, 1979; Philipson, 1973; Schuman and Polkowski, 1975; Sutherland and Cressey, 1970; Taintor, 1974; Tolone and Dermott, 1975). The adolescent's tendency toward "gang behavior" (Havighurst, 1972), and his or her drives and needs to belong to the peer group (Erikson, 1963), make peer influence a natural factor in a youth's decision to use drugs.

Another reason peer pressure might be influential is due to contemporary society's socialization processes and family structure. For example, Levine and Kozak (1979) suggest that deficient socialization and inadequate parenting are possible explanations for why peer pressure is influential in youth delinquent behaviors.

Each of the above-mentioned variables has been demonstrated to be related to substance use. It was hypothesized that several indicators would serve as a better source of estimation of substance use than any one factor 
alone. Therefore, the proposed model tested in this study used health beliefs, peer substance use, and demographics to estimate personal substance use. The purpose of this study was to examine the strengths of the relationships between these variables in a rural middle school population.

\section{METHOD}

\section{Sample}

The study's population was one school system in Michigan's Upper Peninsula and one school system in northeastern Wisconsin. This geographic region was chosen for two reasons: (1) earlier research had demonstrated that substance abuse was a problem in this specific population (Sarvela and McClendon, 1983a, 1987; Sarvela et al., 1986), and (2) limited research has been conducted concerning the unique drug abuse problems of rural America.

The two towns fell under the rubric of "rural" when using the National Institute on Drug Abuse (NIDA, 1981) classification system (that being geographic regions with populations under 25,000 people outside of a Standard Metropolitan Statistical Area). The two populations added together did not total 25,000. Each school system enrolled students who lived in town and outside of the city limits. The population density of the Michigan county was approximately 25 per square mile, while the Wisconsin county's population density was 28.5 per square mile.

All students in the 1983-1984 seventh grade classes of the two school systems were eligible to participate in the study, contingent upon parental approval. Letters of consent were sent to the parents outlining the purpose and procedures of the study. Of the 350 students in both schools, 265 (or $75.7 \%$ ) of the sample received parental permission to take part in the study. Males comprised $43 \%$ of the sample. With regard to religion, $44.5 \%$ of the sample was Protestant, while $43.7 \%$ indicated that they were of Catholic background. An additional $11.7 \%$ of the students responded to either the "none" or "other" category of the religion question.

\section{Research Design and Instrumentation}

Data for this study were based on a self-report questionnaire administered during January and February 1984. The instrument used in the study was developed by the investigators and pilot tested twice: (1) during the initial needs assessment (1981, $N=496)$ and (2) the field test (1982, $N$ $=181$ ). The instrument pilot tests were administered in the Michigan school during the two years prior to the actual study. Due to grade advancement, 
no student taking part in the present study had been exposed to the questionnaire beforehand. The surveys were administered by school teachers and guidance counselors in the school classrooms. The instrument cover sheet emphasized that participation in the study was voluntary and that the answer sheets were not to be reviewed by anyone except the principal investigator.

Based on the results of the pilot tests, appropriate changes were made in the survey instruments, such as the rewording of questions, the deletion of poor items, and the addition of questions not included in the earlier surveys that were considered important after examining the pilot test data. From these data, it was determined that alcohol, cigarettes, and marihuana would be the most important drugs on which to focus in this population, since their prevalence rates were highest. Cocaine was added to the questionnaire because of recent media attention concerning its use. Chemicals such as LSD, mescaline, heroin, and barbiturates had an extremely low reported frequency of use in the field tests, and therefore were not examined in the present study.

The survey was composed of four major parts, each component reflecting a specific element of the regression model tested: personal drug use, health beliefs, peer use, and demographic factors (sex and religion). Measures of substance use examined the frequency of reported peer and personal substance use, quantities of substance use (for alcohol and cigarettes), and the number of peers who used each substance.

The health belief questions asked the student to rate the harmfulness of using a particular substance on a 5-point Likert scale. The possible responses ranged from very bad to very good for one's health.

Test-retest reliability strategies were used to measure the relative stability of the instrument over time. Using the total populations of the needs assessment and the field test as the unit of analysis, the results yielded no major variations between the findings. The trends in drug usage were identical at each point in time; that is, alcohol was the most commonly used drug, followed by cigarette smoking, then marihuana.

The second method of assessing instrument reliability tapped the amount of systematic error that was present due to subjects' intentional misreporting. This reliability measure utilized lie-scale questions based on bogus drug usage, which produced a measure of respondent honesty in answering questions. In the field test, the reliability of these measures was above $94 \%$ for each question. For the present study, reported drug use reliability was above $98 \%$ for each lie-scale item.

Instrument validity was appraised using both content and construct validity procedures. Consensual validity procedures were used to examine the content validity of the instrument. With this form of content validity, it is necessary for an external panel of experts to "examine and rate the appropri- 
ateness of each item in the completed instrument" (Green and Lewis, 1986, p. 106). Three reviewers examined the instrument in terms of its content, form, and instructions. On the basis of their comments, changes were made to improve the instrument's overall content and representativeness.

Construct validity was estimated using the correlations between peer and personal substance use. These analyses were conducted to determine the relationships among the various constructs under investigation in this study. (Johnston et al. [1982] have concluded that the high degree of correspondence between personal reported drug use and reported drug use of peers is evidence for the validity of self-report tests; this strategy was employed for the present study.) The strong positive correlation between reported peer and personal drug use in this population when using this data collection instrument (e.g., Sarvela and McClendon, 1983b; Sarvela et al., 1986) suggests that a satisfactory degree of construct validity is present in this instrument as well.

\section{Regression Analysis}

The regression model tested in this study was as follows:

$$
Y=\beta_{0}+\beta_{1} x_{1}+\ldots \beta_{6} x_{6}+E
$$

where $Y$ is the frequency of substance used, $x_{1}$ is the individual's health beliefs toward substance, $x_{2}$ is the peer frequency of use of the substance, $x_{3}$ is the peer quantity of use of the substance, $x_{4}$ is the number of peers who use the substance, $x_{5}$ is the sex of the subject, $x_{6}$ is religion, and $E$ is the residual.

\section{RESULTS}

The data suggested that approximately $59 \%$ of the sample used alcohol at least one time per year, while $8.1 \%$ of the population smoked cigarettes at least once a year. Only $2.4 \%$ of the students reported using marihuana at any frequency, and even fewer $(0.8 \%)$ of the students reported using cocaine. In terms of quantity of alcohol use, the majority of the drinkers $(41.5 \%)$ reported that they drank 1-2 drinks per sitting. With regard to the number of cigarettes smoked (quantity), all smokers indicated using 1-9 cigarettes per day.

The trends concerning peer drug use were similar to those of reported personal use, although peer use was reported at slightly higher rates. Alcohol was the most popular drug reported to be used by peers, followed by 


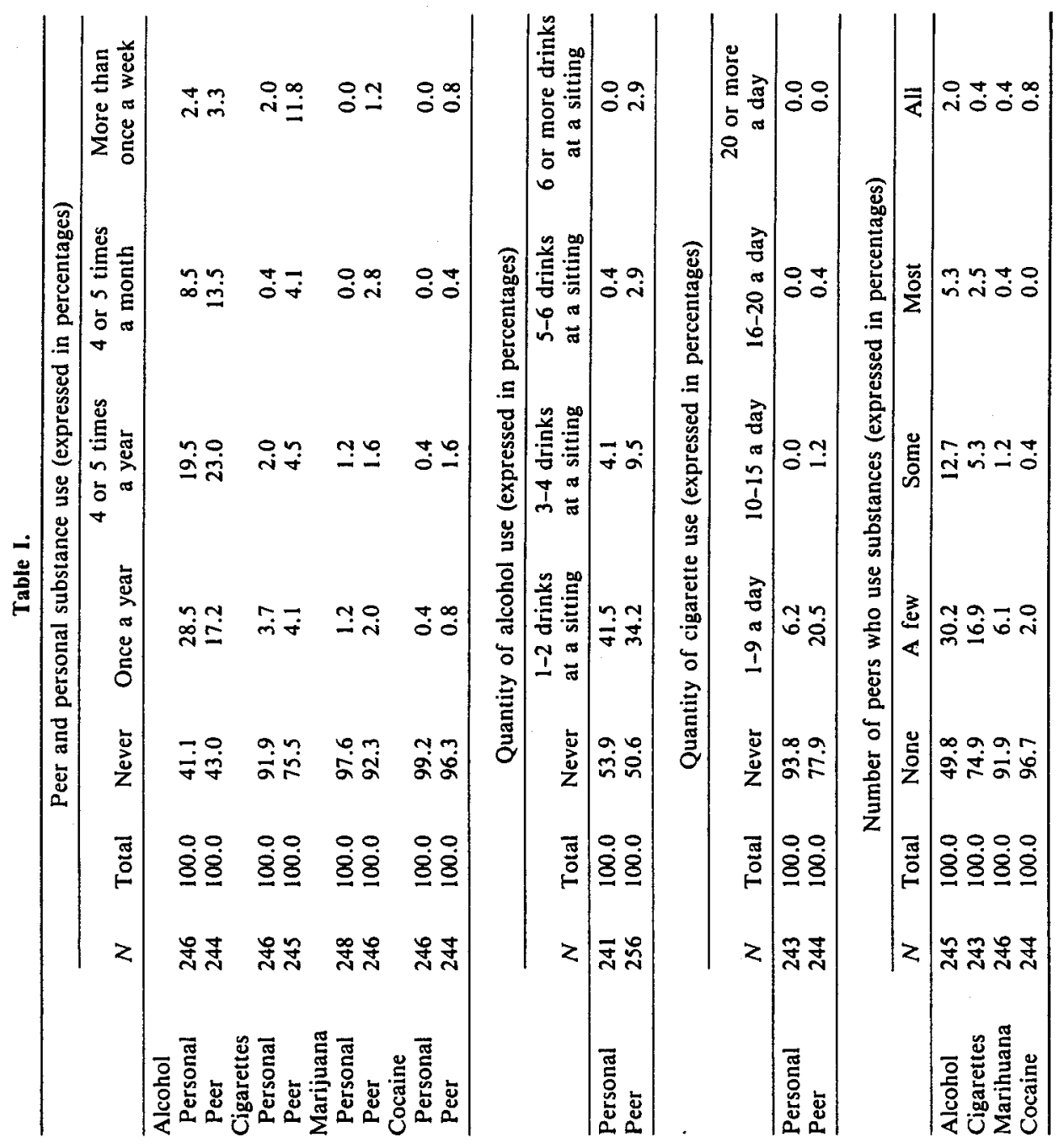


Table II. Substance Use Health Beliefs (Expressed in Percentages)

\begin{tabular}{lccccccc}
\hline & $N$ & Total & Very bad & Bad & No harm & Good & Very good \\
\hline Alcohol & 247 & 100.0 & 48.5 & 38.4 & 8.5 & 1.2 & 3.2 \\
Cigarettes & 246 & 100.0 & 48.0 & 41.5 & 6.1 & 1.2 & 3.3 \\
Marihuana & 246 & 100.0 & 82.1 & 11.0 & 2.0 & 0.4 & 4.5 \\
Cocaine & 247 & 100.0 & 85.8 & 7.7 & 0.8 & 0.8 & 4.9 \\
\hline
\end{tabular}

cigarettes, marihuana, and cocaine. Data summarizing peer and personal substance use appear in Table I.

Subject perceptions of the relative risks of engaging in certain substance use behaviors were tapped as well. In general, the following trend was present: cocaine was thought to be the most dangerous, marihuana was the next dangerous, and alcohol and cigarette use were considered the least dangerous of the four drugs examined. These results indicate that a majority of the subjects felt substance use had a negative impact on personal health. Table II shows the results concerning student reported health beliefs.

The results appearing in Table III suggested that significant relationships existed between the drug use rates of adolescents and their peers. The strength of the relationships appeared a function of the drug used. That is, marihuana produced the strongest relationship $(+.96)$ and cigarettes the least powerful $(+.65)$. All substances tested produced a high positive relationship between peer and personal substance use.

The data confirmed the hypothesis that there was a significant relationship (positive correlation) between health beliefs and behavior as well. Table IV shows that cocaine produced the highest correlation $(+.95)$ between personal substance use and its corresponding health beliefs, while marihuana produced a coefficient of +.71 . Alcohol showed moderate relationships, with $\gamma$ values of +.43 and +.47 . Interestingly, while the relationship between the frequency of smoking cigarettes and its corresponding health beliefs showed a significant relationship $(+.46)$, there was no statistically significant relationship between quantity of cigarettes smoked and health beliefs.

Table III. Correlation Between Peer and Personal Substance Use (Goodman-Kruskal Gamma Analysis; $N=222$ )

\begin{tabular}{lccc}
\hline Personal use of & $\begin{array}{c}\text { Number of } \\
\text { peers } \\
\text { who use }\end{array}$ & $\begin{array}{c}\text { Frequency } \\
\text { of peers' } \\
\text { use }\end{array}$ & $\begin{array}{c}\text { Quantity } \\
\text { of peers' } \\
\text { use }\end{array}$ \\
\hline Alcohol frequency & $.68^{a}$ & $.70^{a}$ & $.67^{a}$ \\
Alcohol quantity & $.74^{a}$ & $.73^{a}$ & $.74^{a}$ \\
Cigarette frequency & $.78^{a}$ & $.65^{a}$ & $.73^{a}$ \\
Cigarette quantity & $.80^{a}$ & $.66^{a}$ & $.82^{a}$ \\
Marihuana & $.96^{a}$ & $.89^{a}$ & na \\
Cocaine & $.92^{a}$ & $.93^{a}$ & na \\
\hline
\end{tabular}

${ }^{a} p<.01$. 
Table IV. Correlation Between Health Beliefs and Personal Substance Use (Goodman-Kruskal Gamma Analysis; $N=220$ )

\begin{tabular}{lc}
\hline Personal use of & Health belief \\
\hline Alcohol frequency & $.43^{a}$ \\
Alcohol quantity & $.47^{a}$ \\
Cigarette frequency & $.46^{a}$ \\
Cigarette quantity & $.06 \mathrm{~ns}$ \\
Marihuana & $.71^{a}$ \\
Cocaine & $.95^{a}$ \\
\hline
\end{tabular}

${ }_{p} p<.01$.

The regression models were tested next. These models were very successful in estimating alcohol, cigarette, and marihuana use, accounting for about .50 (alcohol) to .28 (marihuana) of the variance of drug use. The model was unable to account for a statistically significant amount of the variance of cocaine use. Indeed, both marihuana and cocaine $r^{2}$ values were probably low due to the low incidence in use of the substance rather than any theoretical problems with the model. Peer use factors were the strongest predictors of drug use, while health beliefs were significant variables for alcohol and cigarette use. Sex differences were found to be a factor with alcohol use as well (consistent with normative data, males used more alcohol than females). ${ }^{3}$

\section{DISCUSSION}

The data indicated that alcohol use in the study population was much higher than comparable data based on national samples. For example, Johnston et al. (1979) found that $9 \%$ of their target population had first experimented with alcohol at the sixth grade, while the present study indicated that $58.9 \%$ of the subjects used alcohol at least once a year. The use rates of the other drugs were comparable to those found in national samples.

The frequency data suggested that the rates of alcohol use among early adolescents in rural northern Michigan and northeastern Wisconsin is much greater than adolescent alcohol use rates shown in national studies. The results also suggest that alcohol use begins at an earlier age in rural upper Great Lakes communities than it does in the United States as a whole. Because of this, alcohol education in this population should begin during the elemen-

${ }^{3}$ Detailed results of the regression analyses and bivariate zero-order correlation matrix are available upon request from the author. 
tary grades to reduce the prevalence of substance abuse during its incipient stages of development.

Personal drug use was found to be positively correlated with peer drug use. The strength of the relationship was dependent upon the substance used, where marihuana produced the strongest correlation and cigarette smoking the weakest. These data may indicate that individual participation is more important in a peer group that smokes marihuana than in one that uses alcohol or cigarettes. In addition, the data strongly suggest that health education programs in the future should focus on peer drug use and the associated peer pressure. This recommendation is supported by research conducted by Dielman et al. (1985), which has shown that role-modeling methods incorporating mock situations where peer pressure was present reduced cigarette smoking in elementary youth. This strategy may have potential in other drug education programs (e.g., alcohol, marihuana, cocaine) as well.

Health beliefs concerning the use of a particular drug were also found to be significantly related to substance use behavior. In general, students who felt drug use was dangerous for one's health used fewer drugs, while those who felt use was not as dangerous used more drugs. These data suggest that health beliefs may in fact have an impact on an individual's decision to use a particular drug. Shaping appropriate drug use health beliefs at an early age may well be an appropriate health education goal. This objective might best be met through an elementary school health education program that emphasizes healthy living practices. That there were no relationships between quantity of cigarette use and health beliefs suggests that early adolescents may have misconceptions concerning the danger of using cigarettes.

The health belief findings appear to confirm in part the validity of the Ajzen and Fishbein (1980) paradigm as well as the Health Belief Model (i.e., Rosenstock, 1974). Both models suggest that attitudes toward a specific behavior are instrumental in the individual's decision to engage in the behavior. Although causality cannot be determined due to the cross-sectional nature of the design, the existence of a relationship between health beliefs and drug use was established in this analysis.

For the three drugs examined in the regression analysis, peer use of the substance appeared the strongest indicator. Within the peer dimension of the study, the number of peers who used a particular substance produced the strongest $\beta$ weights for cigarette and marihuana use, while the strongest $\beta$ weights for alcohol use were obtained by peer frequency of use of alcohol.

Health beliefs produced significant $\beta$ weights for alcohol and cigarette use, but not marihuana. These data may suggest that youth behave in a manner consistent with their belief structures with certain drugs, such as alcohol and cigarettes, but inconsistently with other substances, such as marihuana. 
This finding may further support cognitive dissonance theory, since it appears that in the case of marihuana use, peer factors override health beliefs in youth decisions to use the substance.

Interestingly, there were no significant differences between Protestants, Catholics, and the "other" religious self-classification category in substance use behaviors. These data suggest that, regardless of religion, substance use behaviors remain relatively consistent in this rural youth population. This may be due to the fact that the students sampled were primarily of the Catholic or Protestant faiths. If Jewish students, Muslims, or students of other religions were studied, religious differences might be more distinct.

With regard to sex, significantly more males than females used alcohol in this population. In accordance with the finding of many other studies, alcohol use among preteens and early teens appeared primarily a male activity. Sex does not, however, appear a moderating variable for the other drugs studied. These data further support the notion that the differences between male and female substance use behaviors are diminishing.

\section{RECOMMENDATIONS}

Peer substance use was by far the best indicator of individual substance use in this population. This may be the key focal point for future success in drug education. In addition, therapists ought to include strategies for coping with peer pressure in their adolescent treatment programs. More detailed research is needed to explore the nature of peer pressure and its effects on drug use. This study has provided data concerning the descriptive multivariate relationships between peer and personal drug use, but has not explored in depth how and why peer pressure influences drug use. A phenomenologically based study might provide better answers to this question.

The findings concerning the relationships between health beliefs and their related behaviors were also positive and should be carefully considered when designing future drug education programs. A drug education curriculum that fosters health beliefs at an early age may be an effective approach to reducing early adolescent substance abuse in its developmental stages. Therapists might focus on developing healthy attitudes toward drug use with their clients, since they appear closely linked to substance use behavior.

Future research is needed to determine whether these findings are applicable to rural upper Great Lakes adolescents alone, or whether they describe adolescents of other rural regions, or even urban areas, as well. A more geographically dispersed sample would greatly enhance the generalizability of the results. 


\section{REFERENCES}

Ajzen, I., and Fishbein, M. (1980). Understanding Attitudes and Predicting.Social Behavior. Prentice-Hall, Englewood Cliffs, NJ.

Ausabel, D. P., Montemayor, R., and Svajian, P. (1977). Theory and Problems of Adolescent Development. Grune \& Stratton, New York.

Becker, C. (1977). Sex and drinking patterns: An old relationship revisited a new way. Social Prob. 24: 482-497.

Brook, J., Lukoff, I., and Whiteman, M. (1977). Peer, family and personality domains as related to adolescent drug behaviors. Psychol. Rep. 41: 1095-1102.

Cahalen, D. (1970). Problem Drinkers: A National Survey. Jossey-Bass, San Francisco.

Dembo, R., Schneider, J., \& Berger, W. (1980). Lifestyle and drug involvement among youth in an inner-city junior high school. Int. J. Addict. 15: 171-188.

Dielman, T. E., Lorenger, A. T., Leech, S. L., Lyons, A. L., Klos, D. M., and Horvath, W. J. (1985). Resisting pressures to smoke: 15 month follow-up results of an elementary school based smoking prevention program. Hygie 4: 28-35.

Eichberg, R., and Bentler, P. (1976). Current issues in epidemiology of drug abuse as related to psychosocial studies of adolescent drug use. In Lettieri, D. (ed.), Predicting Adolescent Drug Abuse: A Review of Issues, Methods and Correlations (Publication No. ADM 81-299). National Institute on Drug Abuse, Rockville, MD.

Erikson, E. H. (1963). Childhood and Society. Norton and Company, Inc., New York.

Erickson, P. G. (1982). Illicit drug use, peer attitudes and perceptions of harmful effects among convicted cannabis offenders. Int. J. Addict. 17: 141-54.

Gersick, K. E., Grady, D., Sexton, E., and Lyons, M. (1981). Personality and sociodemographic factors in adolescent drug use. In Lettieri, D. J., and Luford, J. P. (eds.), Drug Abuse and the American Adolescent (Publication No. ADM 81-1166). National Institute on Drug Abuse, Rockville, MD.

Green, L. W., and Lewis, F. M. (1986). Measurement and Evaluation in Health Education and Health Promotion. Mayfield Publishing Company, Palo Alto, CA.

Hamburg, B. A., Kraemer, H. L., and Janke, W. (1975). A hierarchy of drug use in adolescence: Behavioral and attitudinal correlates of substantial drug use. Am. J. Psychiatr. 132: $1155-1163$.

Hartnoll, R., and Mitcheson, M. (1973). Attitudes of young people toward drug use. Bull. Narcot. 25: 9-24.

Havighurst, R. J. (1972). Developmental Tasks and Education. Longman, New York.

Jessor, R. (1976). Predicting time of onset of marijuana use: A developmental study of high school youth. J. Consult. Clin. Psychol. 44: 125-1134.

Johnston, L. D., Bachman, J. G., and O'Malley, P. M. (1979). 1979 Highlights Drugs and Nations High School Students: 5 Year National Trends (Publication No. ADM 80-930). Department of Health, Education and Welfare, Washington, DC.

Johnston, L. D., Bachman, J. G., and O'Malley, P. M. (1981). Highlights From: Student Drug Use in America, 1975-1981 (Publication No. ADM 82-1208). National Institute on Drug Abuse, Rockville, MD.

Johnston, L. D., Bachman, J. G., and O'Malley, P. M. (1982). Student Drug Use, Attitudes and Beliefs: National Trends 1975-1982 (DHHS Publication No. ADM 83-1260). The National Institute on Drug Abuse, Rockville, MD.

Kamili, K., and Steer, R. A. (1976). Attitudes toward alcohol and drug use and abuse: Demographic and correlational data. Int. J. Addict. 10: 737-760.

Kinder, B. W. (1975). Attitudes toward alcohol and drug use and abuse: Demographic and correlational data. Int. J. Addict. 10: 37-760.

Kirk, R. S. (1979). Drug use among rural youth. In Deschner, G. M., and Friedman, A. S. (eds.), Youth Drug Abuse. Lexington Books, New York.

Levine, E. M., and Kozak, C. (1979). Drug and alcohol use, delinquency and vandalism among upper and middle class pre- and post-adolescents. J. Youth Adoles. 8: 91-101.

London, F. B. (1982). Attitudinal and social normative factors as predictors of intended alcohol abuse among 5th and 6th grade students. J. School Health 52: 244-249. 
Napier, T. L., Carter, T. J., and Pratt, M. C. (1981). Correlates of alcohol and marijuana use among high school students. Rural Sociol. 46: 319-332.

NIDA. (1981). Treatment Research Report: Drug Abuse in Rural America. (Publication No. ADM 81-1050). Author, Washington, DC.

Nyberg, K. L. (1979). Drug abuse and drug programs in rural America. In DuPont, R. I., Goldstein, A., and O'Donnell, J. (eds.), Handbook on Drug Abuse. National Institute on Drug Abuse, Rockville, MD.

Philipson, R. (1973). Adolescent alcohol abuse. Drug Abuse Alcohol. Newslett. 2: 4.

Rosenstock, I. M. (1974). Preventive health behavior. In Becker, M. (ed.), The Health Belief Model and Personal Health Behavior. Health Educat. Monogr. 2 (Whole No. 4).

Sarvela, P. D., and McClendon, E. J. (1983a). Early adolescent substance use/abuse in rural northern Michigan. Catalyst 2: 62-67.

Sarvela, P. D., and McClendon, E. J. (1983b). Correlates of early adolescent substance use in rural northern Michigan. J. Youth Adoles. 12: 319-332.

Sarvela, P. D., and McClendon, E. J. (1987). Early adolescent alcohol abuse in rural northern Michigan. Commun. Mental Health J. 23: 183-191.

Sarvela, P. D., Takeshita, Y. J., and McClendon, E. J. (1986). The influence of peers on rural northern Michigan early adolescent marihuana use. J. Alcohol Drug Educat. 32: 29-39.

Seffrin, J. R., and Seehafer, R. W. (1976). A survey of drug use beliefs, opinions and behavior among junior and senior high school students: part one: Group data. J. School Health 46: $263-268$.

Skiffington, E. W., and Brown, P. M. (1981). Personal, home and school factors related to 11 th graders' drug attitudes. Int. J. Addict. 16: 879-892.

Schuman, S., and Polkowski, J. (1975). Drug and risk perception of ninth grade students: Sex differences and similarities. Commun. Mental Health J. 11: 184-191.

Sutherland, E., and Cressey, D. (1970). Criminology. Lippincott, New York.

Taintor, Z. (1974). The "why" of youthful drug abuse. J. School Health, 44: 26-29.

Tolone, W. L., and Dermott, D. (1975). Some correlates of drug use among high school youth in a rural midwestern community. Int. J. Addict. 10: 761-777.

Weschler, H., and McFadden, M. (1979). Drinking among college students in New England. J. Studies Alcohol. 40: 969-996. 